\title{
Temporal and Spatial Analysis of Alpha and Beta Activity Concentration at Al-Tuwaitha Site, Baghdad
}

\author{
Wedyan G. Nassif*, Basim I. Wahab*, Monim H. Al-Jiboori*† and Abdulrahhman B. Ali** \\ *Atmospheric Sciences Department, College of Science, Mustansiriyah University, Baghdad, Iraq \\ **Remote Sensing and GIS Department, College of Science, University of Baghdad, Baghdad, Iraq \\ $\dagger$ Corresponding author: Monim H. Al-Jiboori; mhaljiboori@gmail.com
}

Nat. Env. \& Poll. Tech.

Website: www.neptjournal.com

Received: 14-02-2020

Revised: $12-03-2020$

Accepted: 21-05-2020

Key Words:

Airborne radioactivity

Alpha/beta particles

Contamination rose

\begin{abstract}
Temporal and spatial analysis of air particulates sampling collection from the in and outside the Al-Tuwaitha, south of Baghdad, was carried out to measure daily gross alpha and beta activity concentrations (AAC and BAC) during the period from January to April of 2017. The results show that most frequencies are within the interval $1-1.49 \mathrm{~Bq} / \mathrm{m}^{3}$ for $\mathrm{AAC}$ and $3-3.49 \mathrm{~Bq} / \mathrm{m}^{3}$ for BAC. Also, the radioactivity levels within the site for both $A A C$ and $B A C$ were found to be higher than those around the outside. Across all air samples at the studied site, the monthly arithmetic means were $3.0 \pm \cdot, 0$ and $6.7 \pm 0.9 \mathrm{~Bq} / \mathrm{m}^{3}$ for both AAC and BAC. It was found that a hotspot for both AAC and BAC in air layer with values of 4.0 and $8.5 \mathrm{~Bq} / \mathrm{m}^{3}$ respectively situated at ITR-5000 reactor northwest of the site, which is a major source of radioactive contamination, but with wind action. This contamination disperses according to its prevailing direction that is southeast. $6.7 \pm 0.9$
\end{abstract}

\section{INTRODUCTION}

In air near the surface, most of the radioactive materials (e.g. uranium and thorium series and the isotope of potassium) at nuclear locations, nuclear weapons testing, or nuclear accidents are continuously emitting harmful ionizing radiations containing energetic charged particles such as alpha and beta. One of these common locations is Al-Tuwaitha nuclear research centre, which was used for nuclear activities, so contains significant amounts of radioactive materials. Alpha and beta particles have adverse health effects on human and animals (somatic and genetic) (Peirce et al. 1998).

Knowledge of the radioactivity levels in the surface air of Al-Tuwaitha site is an important prerequisite for planning work areas and for anticipated future uses of the remediated site when inhaled or ingested (Chesser et al. 2009).

In recent years, several local and international studies about the contaminated location for Al-Tuwaitha have been carried out by many Iraqi researchers. They investigated the radioactivity in analysing the different soil samples (Zaboon et al. 2013, Jarjies et al. 2013) taken from various places at the site and also an assessment of radiation hazards for plants species growth (Mansour et al. 2017). For example, Zaboon et al. (2013) analysed 201 soil samples collected by the Ministry of Science and Technology and then using geographical information system (GIS) they presented maps of radioactive doses contamination. They determined the highest radiation dose rate with $140 \mathrm{mrad} / \mathrm{hr}$ as a hotspot in the site.

Unfortunately, there are a few studies that investigate the analysis of measurements of gross alpha and beta activity concentration (will be symbolled as AAC and BAC, respectively) in the surface air layer at Al-Tuwaitha site. Salih et al. (2018) presented the results of AAC and BAC for selected places within and around the site, which showed that it has natural nuclides that are the daughters of the thorium and the uranium series. These radioactive decays are radon isotope escaping from the soil and ascending into the air. While in the present study, a further attempt to reanalyse the measurements published in this reference with absolutely different analysis from the scope of its objective aims. Here the purpose of this paper is to present the (1) spatial analysis of both AAC and BAC, (2) frequency distributions for specified intervals of these concentrations, (3) AAC and BAC roses, (4) daily variation during the study period, (5) comparison between AAC inside and outside of the studied site as well as for BAC, and finally (6) finding a simple empirical relation between $\mathrm{AAC}$ and BAC.

\section{MATERIALS AND METHODS}

\section{Air Radioactivity}

Radioactivity is the term used to describe the disintegration of atoms. Some materials are unstable. Therefore, their nuclides 
disintegrate or decay, the atom can release energy in the form of radiation (Eisenbud \& Gesell 1997). We frequently receive internal exposure from these elements taking into our bodies through the air we breathe. Continuous particulate air monitors are used for measuring releases of airborne particle radioactivity (APR) from the facility, for protection of plant personal, monitoring the air in the reactor containing structure to detect leakage from the reactor systems and to control ventilation fans when the APR has exceeded the defined threshold.

The activity concentration of a radionuclides alpha and beta is the activity of these in a radioactive substance in an air divided by the volume of the air. The change in counting and background rates represents the number of spontaneous nuclear transformations taking place in the relevant number of radionuclides in a time interval $(\mathrm{t})$ divided by this time.

$$
\mathrm{AAC} / \mathrm{BAC}=\frac{\text { counting rate (alpha/beta) }- \text { background rate (alpha/beta) }}{\Delta \mathrm{t} * \mathrm{~V} * \mathrm{E}_{\mathrm{f}}}
$$

Where, $\mathrm{E}_{\mathrm{f}}$ is the filter efficiency. Thus, the unit of activity concentration in SI is the Becquerel per cubic meter $\left(\mathrm{Bq} / \mathrm{m}^{3}\right)$, whereas $1 \mathrm{~Bq}=1$ disintegration/sec. $\mathrm{Bq}$ is a unit to express the strength of radioactivity.

\section{Al-Tuwaitha Site}

Al-Tuwaitha site as the foundation of Iraq's nuclear research centre is located about $18 \mathrm{~km}$ southeast of Baghdad and $1 \mathrm{~km}$ east of the Tigris river, which covers an area about $1.3 \mathrm{~km}^{2}$. Geographically, it is situated at latitude $33^{\circ} 10^{\prime \prime}-33^{\circ} 15^{\prime \prime} \mathrm{N}$, longitude $44^{\circ} 29^{\prime \prime}-44^{\circ} 35^{\prime \prime} \mathrm{E}$ and $32 \mathrm{~m}$ above mean sea level (Fig. 1).

The site was established in 1967 for legitimate nuclear activities until its final closure in 2003. Large earthen beams (approximately $2.6 \mathrm{~km}$ length and $30 \mathrm{~m}$ high) were placed around the key distinct nuclear key facilities to fortify them. These facilities were comprised of 90 buildings dedicated to two reactors (Osiraq and IRT-5000), fuel fabrication, plutonium separation uranium enrichment, radioactive waste treatment and storages, several research laboratories and many others (Chesser et al. 2009) as shown in Fig. 2. Most of these were seriously bombarded during the Gulf War in 1990 in Iraq and then subjected to subsequent looting.

\section{Material and Data}

The data used in this study can be broadly classified into two types: counting alpha/beta rates and wind directions. Observational data for alpha and beta particles were achieved through several steps: first, collection of air samples drawn from the ambient atmosphere in and out the site using high volume particulate sampling (HVPS) 3000 fixed at $1 \mathrm{~m}$ high. This device was operated with a typical airflow rate of between 10 and $15 \mathrm{~m}^{3} /$ hour. The instrument was put $20 \mathrm{~m}$ away from the building with a sampling period of 1 hour with collection efficiency $99 \%$. The process of aspiration was done

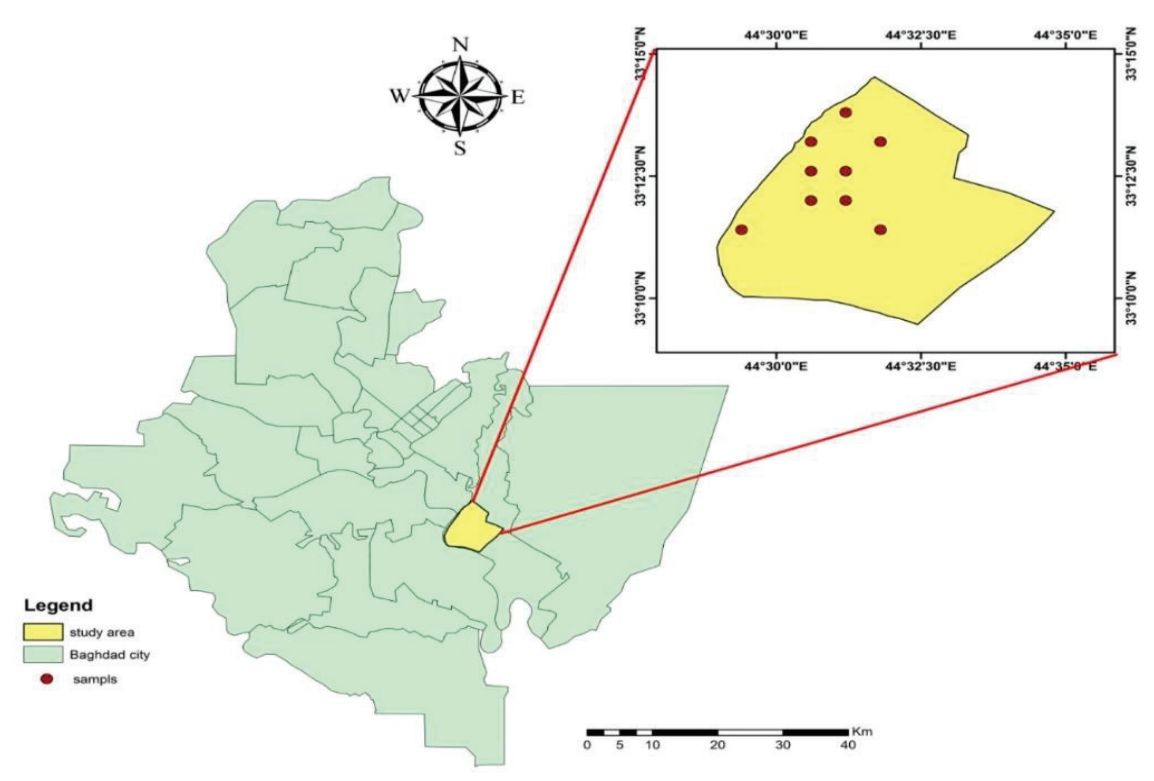

Fig. 1: Map of Al-Tuwaitha site showing some measurement locations $(\bullet)$ plotting by ArcGIS. 


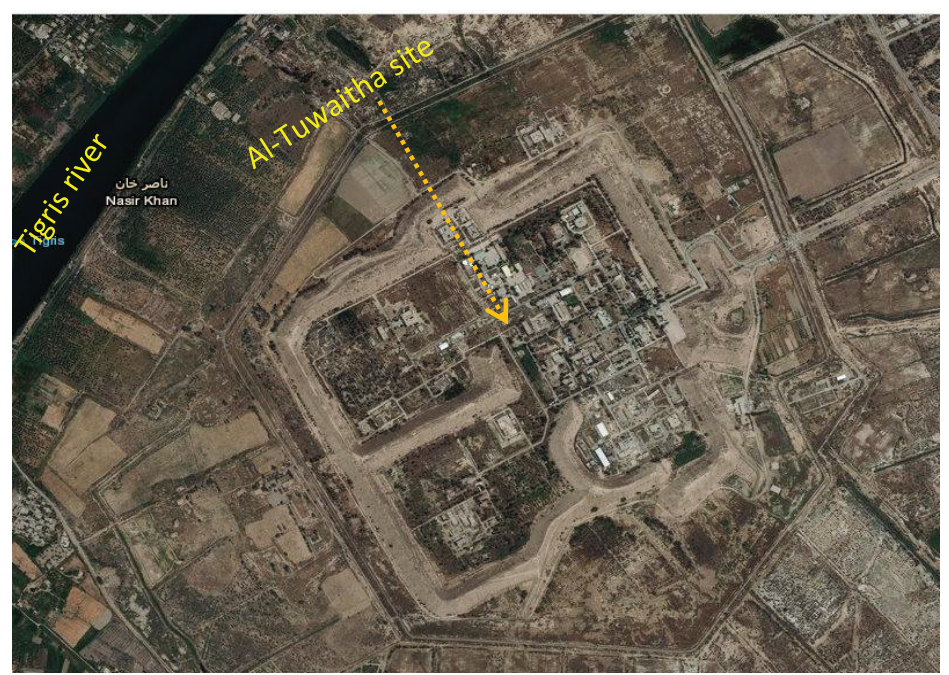

Fig. 2: Aerial satellite image for Al-Tuwaitha nuclear research site.

using an air filter type no. 373030, glass fibre with radius 2.75 $\mathrm{cm}$. The number of samples is 50 taken at various places to cover inside (45) and outside (5), which can be considered as background levels of alpha and beta particles. Second, the above filters were analysed by alpha-beta sample counter Ludlum (model 3030, American originated) to measure simultaneous alpha and beta particles. The feature of this instrument with its other structures can be found in reference (Ludlum measurements 2020) for more details. Before using the device, calibration and quality control check were done using standard sources supplied by the manufacturer.

After ending the aspiration time (1 hour) by HVPS, all filters removed and put in Ludlum for 1 minute to count alpha and beta rates. This step was repeated 3 times and then the average value was calculated. Mean of these rates were substituted in Equation (1) to compute AAC and BAC.

\section{RESULTS AND DISCUSSION}

\section{Frequencies for $\mathrm{AAC}$ and $\mathrm{BAC}$}

Daily activity concentrations of alpha and beta measured in the atmosphere of Al-Tuwaitha site are classified to several intervals with constant length of 0.5 and $1 \mathrm{~Bq} / \mathrm{m}^{3}$ for alpha and beta reported in $\mathrm{X}$-axis of Figs. 3a and $3 \mathrm{~b}$ respectively, which show the frequency distributions for the AAC and BAC values. Highest frequencies are found at the third interval
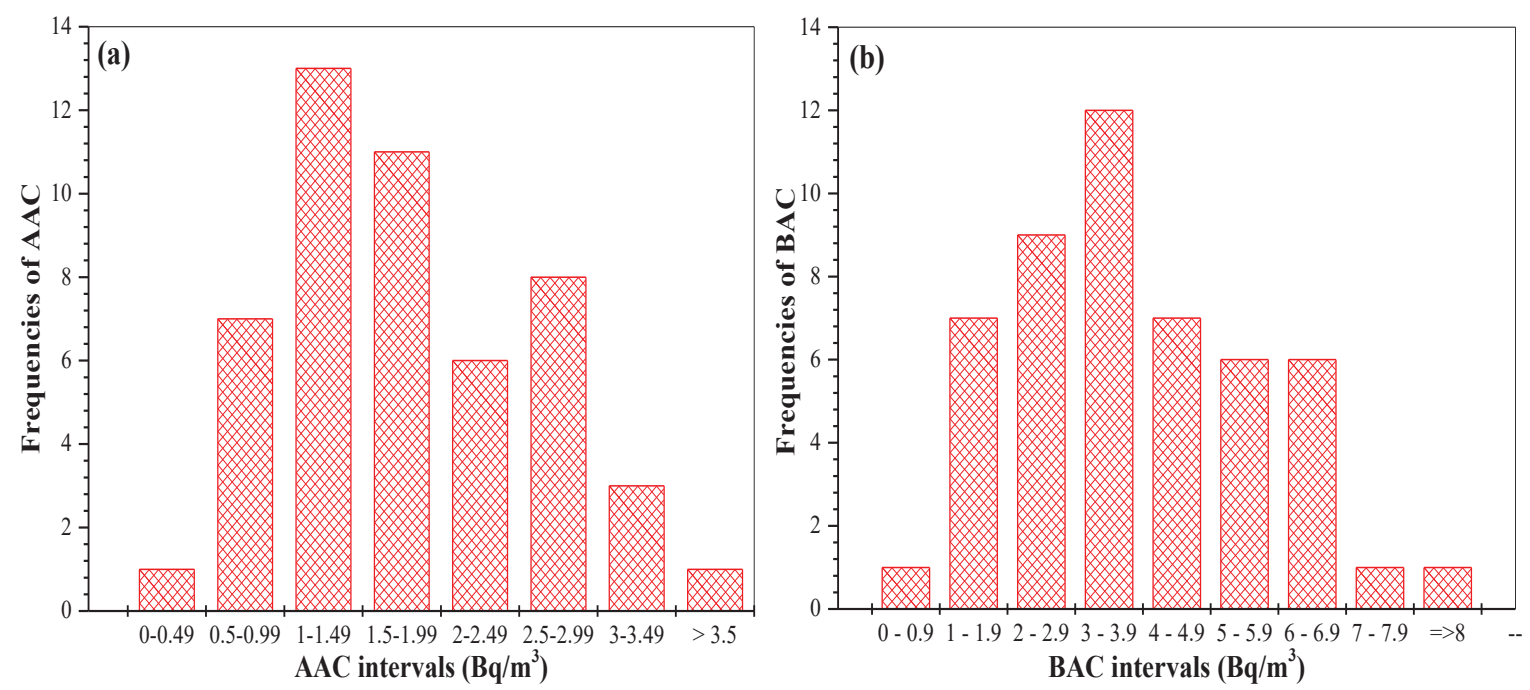

Fig. 3: Frequency distributions for (a) alpha and (b) beta activity concentrations at Al-Tuwaitha. 
(1-1.49) Bq $/ \mathrm{m}^{3}$ with 13 times for AAC (Fig. 3a) while at fourth one (3-3.9) Bq/m $\mathrm{m}^{3}$ for BAC (Fig. 3b). Other intervals have lower frequencies at the beginning and ending of the intervals with a time. Finally, values of intervals for BAC are larger than that of AAC.

\section{Temporal Analysis of AAC and BAC}

Daily variations of AAC and BAC during the study period for both in and outside the site are presented in Fig. 4a and Fig. 4b, respectively. Most of the measurements were taken in the site, so the data points are connected by a line while plotting scatter for data measuring out of the site. At some days, two measures were made for two places on the same day at different times. Thus, their values were averaged to be one. Generally, these figures have some interesting indications: first, values of both AAC and BAC measured at the site are larger than those for outside along the recording period. Another is that all AAC and BAC across the whole site have large values in January and gradually decrease to be minimum in April. Lastly, the behaviours of AAC and BAC are approximately similar but with different magnitudes, whereas BAC has large values. The same results were also recorded in the air of Tehran nuclear research centre (Arkian et al. 2006).

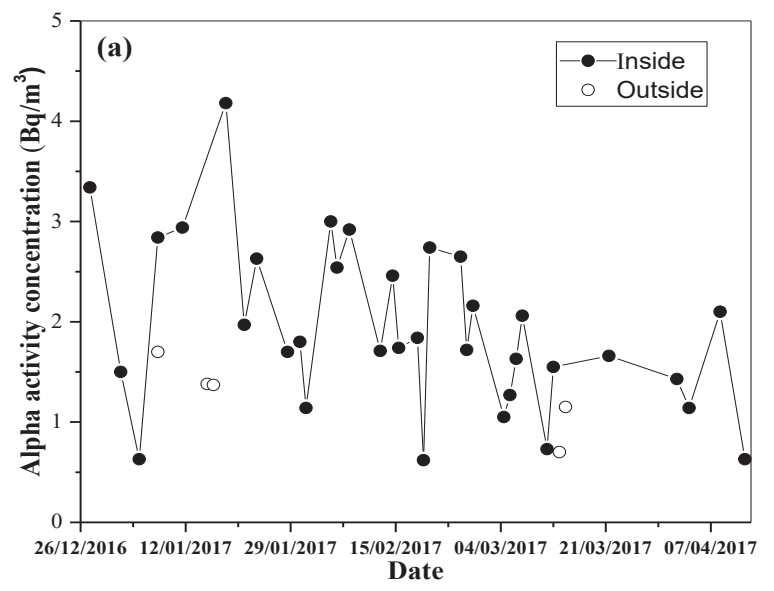

Now we are going to analyze these results by taking averages of AAC and BAC values over each month with calculating standard deviation as illustrated in Table 1 . Winter months represented by January and February have large AAC/BAC values for both in and outside comparing to spring months (March and April). Large AAC and BAC values in the site across all months are fair respect to those recorded around the site. As shown in the last row of Table 1 , the total average of all months of AAC and BAC in the site $1.84 \pm 0.5$ and $4.0 \pm 1.1 \mathrm{~Bq} / \mathrm{m}^{3}$ are larger than those of outside $\left(1.2 \pm 0.4\right.$ and $\left.2.7 \pm 0.8 \mathrm{~Bq} / \mathrm{m}^{3}\right)$, respectively.

According to the above discussion, the AAC and BAC behaviours are almost the same, and therefore now trying to examine the relationship between their values. Fig. 5 shows the linear relation between them which is very good in the air layer with correlation coefficient $\left(\mathrm{R}^{2} \quad 0.9\right)$. This implies that radionuclides (alpha and beta) present due to man-made sources in the site might be responsible for radioactive contamination of the air at the site. The results obtained above show that AAC and BAC values in the site are mostly higher than those of values surrounding the site.

\section{Spatial Analysis}

To execute spatial analysis, digital map layers including

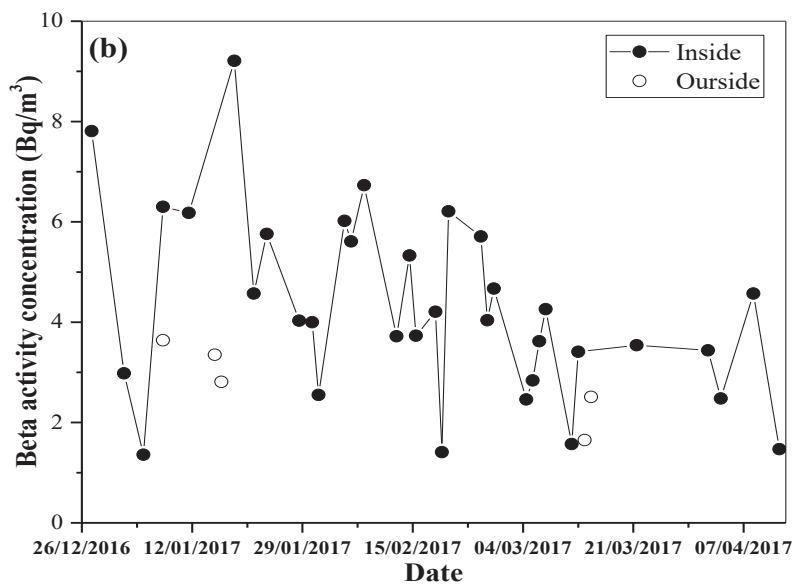

Fig. 4: Daily variations of (a) alpha and (b) beta activity concentrations in- and outside Al-Tuwaitha site.

Table 1: Monthly averages of AAC and BAC with their standard deviations within and outside of Al-Tuwaitha nuclear site.

\begin{tabular}{|c|c|c|c|c|c|c|c|c|}
\hline \multirow[t]{2}{*}{ Months } & \multicolumn{4}{|c|}{ Alpha activity concentration $\left(\mathrm{Bq} / \mathrm{m}^{3}\right)$} & \multicolumn{4}{|c|}{ Beta activity concentration $\left(\mathrm{Bq} / \mathrm{m}^{3}\right)$} \\
\hline & Inside & St. dev. & Outside & St. dev. & Inside & St. dev. & Outside & St. dev. \\
\hline January & 2.4 & 1 & 1.5 & 0.2 & 5.2 & 2.3 & 3.3 & 0.4 \\
\hline February & 2.1 & 0.7 & - & - & 4.6 & 1.5 & - & - \\
\hline March & 1.4 & 0.4 & 0.9 & 0.3 & 3.0 & 0.9 & 2.1 & 0.6 \\
\hline April & 1.3 & 0.6 & - & - & 2.9 & 1.3 & - & - \\
\hline Average & 1.8 & 0.5 & 1.2 & 0.4 & 4.0 & 1.1 & 2.7 & 0.8 \\
\hline
\end{tabular}




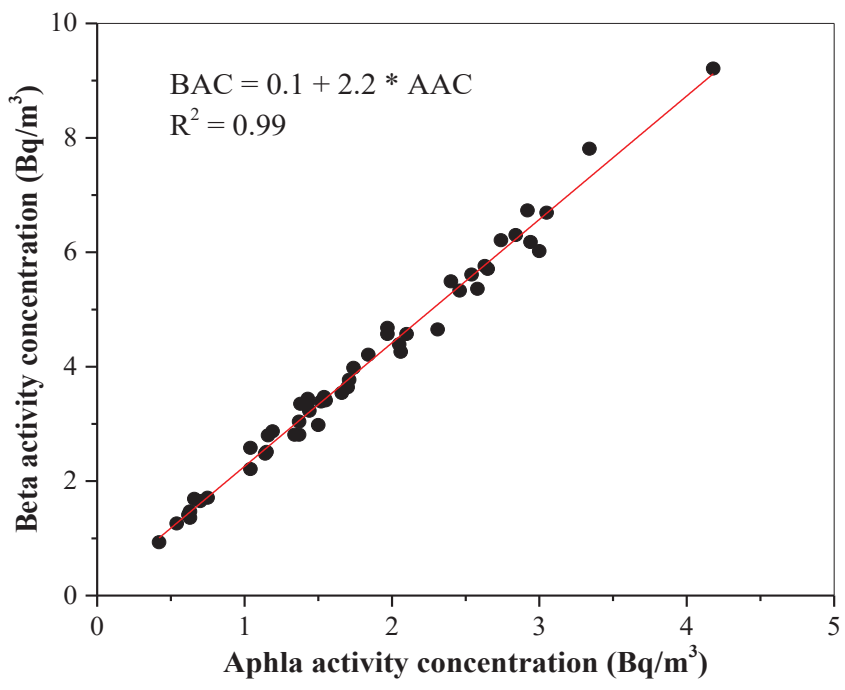

Fig. 5: Correlation of AAC and BAC in the air layer.

contours for AAC and BAC were created by GIS. The mapping procedure had started by converting geographic coordinates for all sample locations to universal transverse Mercator coordinates. These samples were indicated by point shapefile (vector), so it was converted to raster through interpolation using Kriging methods in ArcGIS version 10.4.1 software. Kriging technique is the most relevant method compared to other interpolation techniques in which the process of using points with known values to predict values at other unmeasured points as well as it aims to minimize the variance of the error (Al-Timimi et al. 2012).
However, data are interpolated to display a continuous surface as a visual display.

The spatial interpolation maps of both $\mathrm{AAC}$ and $\mathrm{BAC}$ in the study area are shown in Fig. 6a and Fig. 6b, respectively. The patterns of contours in these two figures appear almost the same. There is a clear hotspot with the value of $4.0 \mathrm{~Bq} / \mathrm{m}^{3}$ for AAC (Fig. 6a) and 8.7 Bq/ $/ \mathrm{m}^{3}$ for BAC (Fig. 6b) centred over contaminated facility (e.g. Osiraq and IRT-5000), while a small value of both $\mathrm{AAC}$ and $\mathrm{BAC}$ to the west and moderate values to the east. Highest values of them are concentrated in the northwest. The location of the contaminated hotspot has serious problem especially
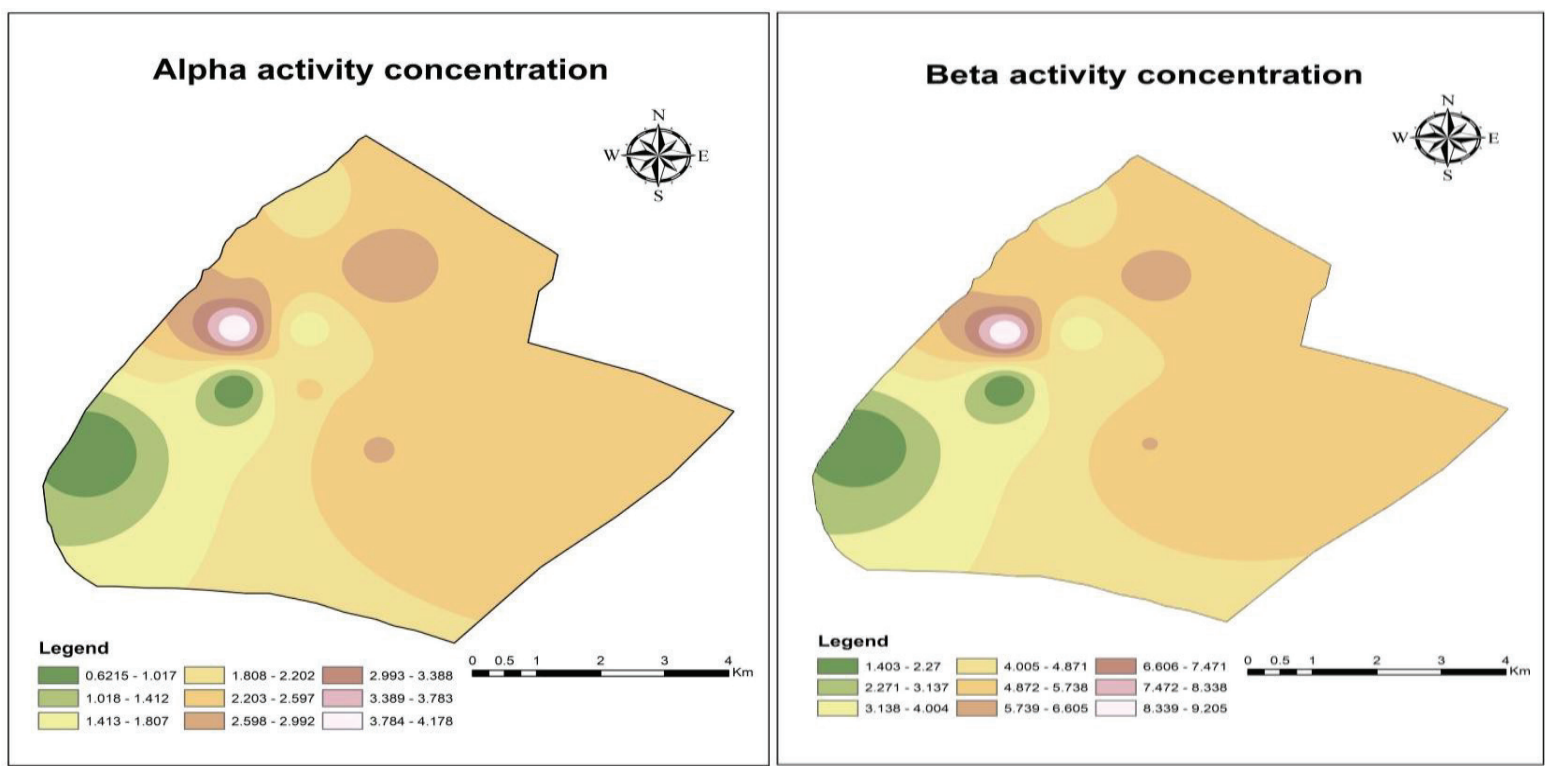

Fig. 6: Spatial analysis map for the distribution of AAC (left) and BAC (right). 

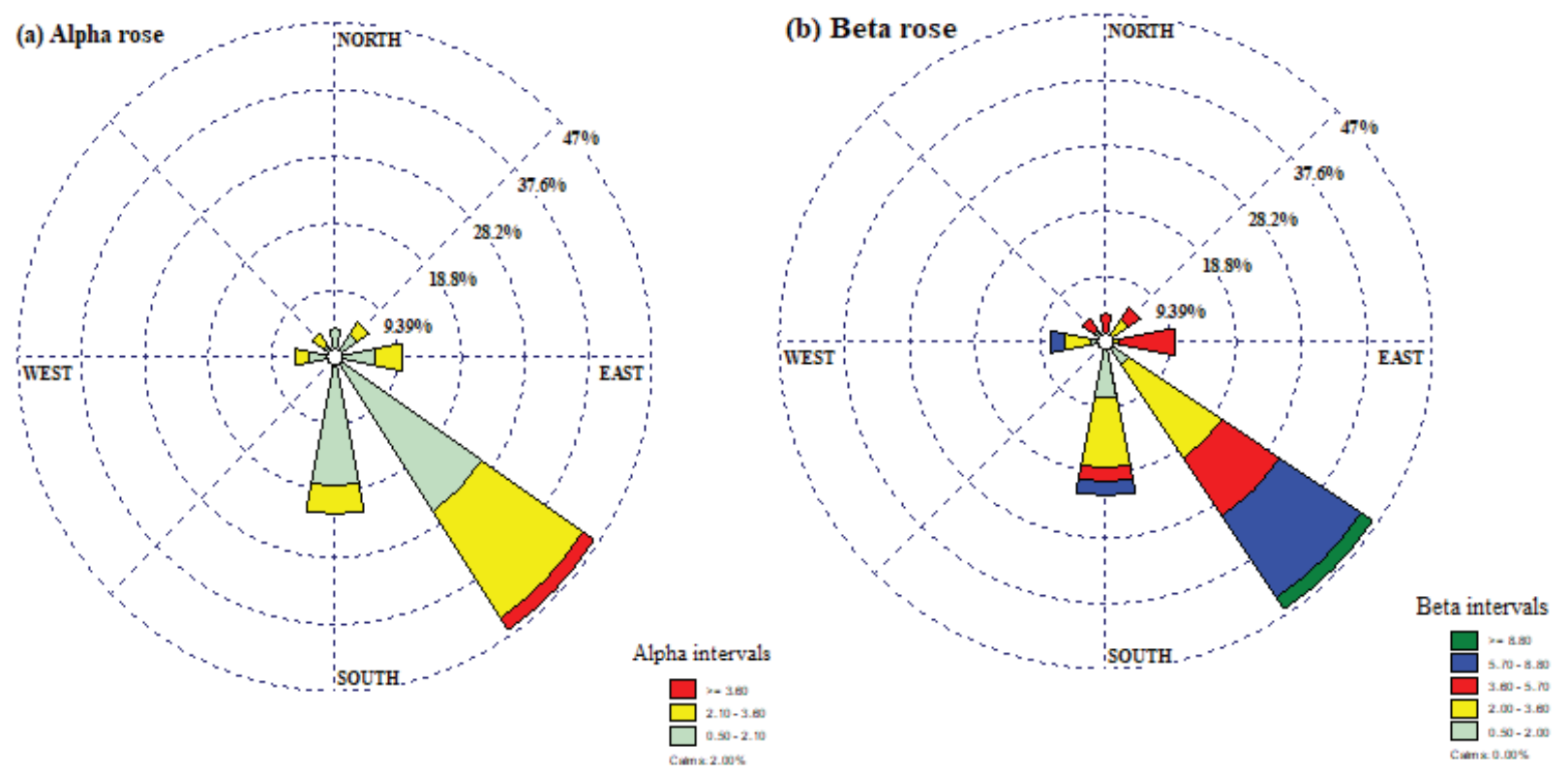

Fig. 7: Contamination roses for (a) alpha and (b) beta activity concentration at Al-Tuwaitha site.

when the prevailing wind direction is frequently coming from the northeast as will be shown in the next subsection.

\section{ACC and BAC Roses}

A contamination rose is a graphical presentation of alpha and beta activity concentrations associated with each wind direction. This was drawn on a circular plot using eight directional sectors resolution. From these plots, it can be used to find the wind directional $\mathrm{AAC}$ and $\mathrm{BAC}$, major source regions of the contamination of interest and help in identifying the direction associated with higher or lower concentrations (Said 2011).

Daily data of wind directions associated with measured $\mathrm{AAC}$ and BAC were drawn to depict the frequencies of the times that contamination levels exceeded background levels. The AAC and BAC roses were created with WRPOLT View-version 8.0.2 (Lakes Environmental 2018), as shown in Fig. 7a and Fig. 7b, respectively. These figures were generated by the frequency of AAC and BAC for each direction of wind some particular concentration. Thus, the western area of Al-Tuwaitha site has higher frequencies of high AAC and BAC as illustrated in Fig. 7a and Fig. 7b respectively, while low frequencies are from outside the site with north and northwest. This indicates that the areas associated with northwest and north directions, which have major sources of the radioactivity of alpha and beta, have a great impact on the southeast areas. Inversely, areas on the southwest direction have relatively low AAC and BAC.

\section{CONCLUSIONS}

The gross alpha and beta activity concentrations were detected in the collected aerosol samples. The primary conclusion is that AAC and BAC in Al-Tuwaitha nuclear site show high levels with hotspot over ITR 5000 compared to the surrounding areas of the site. Across all sampling collections, values of BAC are larger than AAC. Monthly means of AAC and BAC in winter were higher than in spring because of the atmospheric stability on the radioactive nuclides. Wind directions have an important role in distribution and dispersion aerosols as carriers of these nuclides. To the best of our knowledge is to investigate the influences of meteorology in the dispersion and transport of radioactivity.

National and international standards considering sampling sites and measuring laboratories should be accurately applied to provide high quality assurance and quality control of the air radioactivity monitoring system.

\section{ACKNOWLEDGMENTS}

The authors are grateful to Mustansiriyah University for the acceptance of this work.

\section{REFERENCES}

Al-Timimi, Y. K., George, L. E. and Al-Jiboori, M. H. 2012. Drought risk assessment in Iraq using remote sensing and GIS techniques. Iraqi Journal of Sciences, 53(4): 1078-1082. 
Arkian, F., Salahinejad, M. and Amidi, J. 2006. Analysis of gross alpha, gross beta activities and beryllium-7 concentrations in surface air: their variation and statistical prediction model. Iranian Journal Radiat. Res., 4(3): 155-159.

Chesser, R. K., Rodgers, B. E., Bondarkov, M., Shubber, E. and Phillips, C. J. 2009. Piecing together Iraq`s nuclear legacy. Bulletin of the Atomic Scientists, 19-26.

Eisenbud, M. and Gesell, T. 1997. Environmental Radioactivity: From Natural, Industrial and Military sources (4th ed.). Academic Press, pp. 656.

Jarjies, A., Abbas, M., Fernandes, H. M., Wong, M. and Coates, R. 2013. Prioritization methodology for the decommissioning of nuclear facilities: A study case on the Iraq former nuclear complex. Journal of Environmental Radioactivity, 119: 70-78.

Lakes Environmental. 2018. WRPLOT View, Wind Rose Plots for Meteorological Data. (L. E. Software, Producer) Retrieved from http:// www.weblakes.com/products/wrplot/index.html.
Ludlum measurements 2020. Int. measurements. LUDLUM MODEL 3030 Alpha-Beta Sample Counter manual: 2020.

Mansour, H.L., Al-Bakhat, Y.M. and Karkosh, H.N. 2017. Measurement of radioactivity levels and assessment of radiation hazards for plants species grown at scrap yard (B) at Al-Tuwaitha nuclear site (Iraq). Nuclear, 2(4): 94-98.

Peirce, J.J., Weiner, R.F. and Vesilind, P.A. 1998. Environmental Pollution and Control (4th ed.). Butterworth-Heinemann, pp. 392.

Said, A. Y. 2011. Air quality trends and pollution roses in selection cities of Canada. University of Windsor, Canada.

Salih, N. A., Al-bakhat, Y. M., Al-Rahmani, A. A., Murbar, O. M., Ameen, N. H. and Majed, N. M. 2018. Assessment of radiological air contamination for selected places at Al-Tawaitha nuclear site during winter and spring. Baghdad Science Journal, 15(3): 278-286.

Zaboon, A. T., Al-Obaidy, A. M. and Al-Sharaa, H. M. 2013. Radioactive doses contamination in Al-Tuwaitha nuclear site using GIS techniques. Engineering \& Technology Journal, 31 Part A(9): 1612-1615. 